\title{
Timing of Elective Cesarean Delivery at Term
}

\author{
Raed Salim \\ Department of Obstetrics and Gynecology, Emek Medical Center, Afula, \\ Rappaport Faculty of Medicine, Technion, Haifa, \\ Israel
}

\section{Introduction}

The rate of cesarean delivery is constantly increasing for mothers of all ages, races, and ethnic groups (Martin et al., 2005). In view of that, timing of elective cesarean delivery at term has an essential public health implication. Term gestation, by definition, is a gestation of 37 weeks to 42 weeks from the day of the last menstrual period. Though infants born by elective cesarean delivery within this range are considered term infants, risk of serious perinatal morbidity and mortality may still occur and may differ according to the gestational age within this range.

Delaying delivery until 41 weeks or more will increase significantly the proportion of women who may go into spontaneous labor and consequently deliver by non-elective cesarean delivery rather than an elective one. In addition it has been reported that stillbirth, is almost doubled at 41 weeks of gestation and increase by a factor of up to 5 at 42 weeks as compared with 39 weeks (Meikle et al., 2005; Wood et al., 2008). Accordingly, performing elective cesarean before 41 weeks, if possible, is desirable.

In the other hand, as compared with births at 39 to 40 weeks, births at 37 weeks have been reported to be associated with an increased risk of neonatal morbidity. Compared with newborns delivered vaginally, a significantly increased risk of respiratory morbidity was found among infants delivered by an elective cesarean section at 37 compared to 39 weeks (Hansen et al., 2008). Lack of hormones associated with labor could explain this association. Labor and rupture of membranes may stimulate secretion of catecholamines in the fetus. As a result, a decrease in secretion of fetal lung liquids and an increase in their absorption have been reported. When cesarean sections are carried out before labor, this catecholamine surge is absent (Brown et al., 1983). In view of that, scheduling elective cesarean at 37 weeks is also undesirable.

Since neonatal respiratory morbidity at 38 weeks is still slightly higher compared to 39 weeks, the literature is nearly unanimous in recommending elective cesarean delivery at 39 weeks of gestation. However, delaying elective cesarean delivery from 38 to 39 weeks may have maternal and other fetal consequences that are not always addressed in studies that recommend delaying delivery to 39 weeks (Salim et al., 2009; Salim \& Shalev, 2011).

Delaying delivery for an additional week increases the time that the woman and her fetus is vulnerable to a number of unexpected complications and increases the proportion of women 
who will deliver by non-elective cesarean delivery rather than an elective one. It has been reported that $10 \%$ to $14 \%$ of women may go into spontaneous labor between 38 and 39 weeks of gestation (Salim \& Shalev, 2010; Thomas \& Paranjothy, 2001). The meaning of these numbers is that over $10 \%$ of elective cesarean deliveries scheduled to 39 weeks will likely convert to non-elective ones between 38 to 39 weeks. The incidence may be even greater in public medical centers where the number of elective cesarean deliveries per week is initially limited by the availability of the operating theater. If scheduling starts from 39 weeks, an over booking in a certain week may result in delaying the timing of the scheduled cesarean delivery for some women to 40 weeks or more which may result in even a greater proportion of women presenting in labor before their scheduled cesarean delivery date.

The outcome of this particular group of women is less addressed in the literature when discussing the advantages of elective cesarean deliveries, since the majority of published studies on elective cesarean delivery exclude from statistical analysis women who delivered non-electively before the scheduled date of delivery. Other studies combined this cohort of women with those that delivered electively so that it is impossible to isolate the contribution of non-elective delivery to the outcome. A design centered on the actual delivery route will allow investigators to distinguish between labored and unlabored cesarean deliveries. In studies limited to unlabored cesareans, women who present in labor before their scheduled date of delivery are, by definition, excluded. Excluding these women may overestimate potential benefits and also potential harms because the studies then cannot account for any effect that labor has on outcomes of interest.

A search of PubMed, MEDLINE, EMBASE, and Cochrane Library databases up to February, 2012, did not detect any randomized controlled trial that compared the timing of elective cesarean delivery at 38 or 39 weeks and which investigated both perinatal and maternal outcomes.

In this chapter, I will present in details the perinatal and maternal benefits as well as the consequences resulting from scheduling elective cesarean delivery at 39 weeks compared to 38 weeks.

\section{Perinatal and maternal benefits and consequences}

\subsection{Perinatal benefits}

The main impact of delivery at 39 weeks as compared to 38 weeks is the reduction in neonatal respiratory morbidity.

Newborn and adult lungs function most effectively when almost devoid of liquid in the alveoli and airways, whereas to grow normally the fetal lungs must be distended by a volume of liquid that equals or exceeds the functional residual capacity of newborn and adult lungs (Berger et al., 1998). To create the liquid present in the fetal lungs, the pulmonary epithelium actively pumps Cl- ions into the future air-spaces (Olver \& Strang, 1974). As a result, the fetal lung secretes a liquid which distends the future air-spaces and plays a crucial role in promoting lung growth.

Though liquid is essential for normal fetal lungs development, both experimental (Berger et al., 1996) and clinical (Hales et al., 1993) evidences support the view that prenatal clearance of lung liquid before birth is critical for the establishment of normal respiratory function immediately after delivery. 
Infants delivered by cesarean section take longer than those born vaginally to increase their arterial oxygen levels (Oliver et al., 1961) and to establish adequate pulmonary gas exchange (Palme-Kilander et al., 193). The difference is evident clinically as an excess of respiratory illnesses such as transient tachypnoea of the newborn (Mikner et al., 1987; Hales et al., 1993) or respiratory distress syndrome and hyaline membrane disease (Brice et al., 1977).

Circulating epinephrine, which is known to increase during labor, has been shown to convert the lung of the late-gestation fetal lamb from liquid-secreting to liquid-absorbing through beta2-receptor activation of a $\mathrm{Na}+$ pump located on the apical surface of the pulmonary epithelium (Brown et al., 1983). $\mathrm{Na}+$ channels on the apical (luminal) side of the pulmonary epithelium increase in number with the approach of delivery (Baines et al., 2000). Maturation of this mechanism appears to be under the control of cortisol and thyroid hormone, both of which increase over the last days of gestation (Barker et al., 1991; Wallace et al, 1996).

The view that $\mathrm{Na}^{+}$transport plays a vital role in respiratory adaptation at birth is supported by the finding of transient tachypnea of the newborn or other respiratory failure in babies in which the pump has not been activated or genetically abnormal (Gowen et al., 1988).

The timetable, with which lung liquid volume and secretion decline before term delivery, underlines the importance of the last days of gestation in adapting the fetus for the postnatal life. Lung liquid volume begins to fall before labor (Dickson et al., 1986). In addition the rate of flow of liquid out of the fetal trachea also begins to decline before labor ((Dickson et al., 1986; Olver et al., 1986; Kitterman et al., 1979). A more rapid fall between early and advanced labor then took place (Pfister et al., 2001). This final step in the clearance of lung liquid involves active reabsorption, a process that has been shown to be stimulated by the catecholamine surge which occurs just before the end of labor (Brown et al., 1983). Reabsorption of liquid from the lung is driven by active $\mathrm{Na}+$ transport which then continues to play a dominant role in keeping the air space dry throughout postnatal life. In addition the larynx acts as a one-way valve allowing only liquid outflow under normal circumstances and prevents the entry of amniotic fluid (Brown et al., 1983) probably by a negative intra-pulmonary pressure produced near the end of labor (Pfister et al., 2001).

Existing evidence starkly demonstrates that late gestation and labor are beneficial to the baby for additional reasons. Surfactant synthesis and release are increased during labor (Ballard, 1986). The increasing concentration of cortisol (Bassett \& Thorburn, 1969) and thyroid hormones (Fraser \& Liggins, 1988) in the last days of gestation and during labor itself may accelerate maturation of the lung (Liggins et al., 1988) and play a key role in lung liquid reabsorption (Barker et al., 1991).

The mechanisms that adapt the lung for postnatal life can be seen to include a prolonged and gradual clearance of lung liquid beginning well before the onset of labor, together with an acceleration of clearance once labor is established. The respiratory vulnerability that elective cesarean delivery represents may therefore, not simply be attributable to the absence of labor, but also to the newborn missing out on a process that clears liquid from the lung over a period of days leading up to labor.

According to Bland et al the lungs of rabbits, delivered either vaginally or by cesarean section after a period in labor, contain less water than the lungs of rabbits delivered by 
cesarean section before the onset of labor (Bland et al., 1979). In human babies, Chiswick \& Milner, from measurements of crying vital capacity, and Milner et al, from measurements of thoracic gas volume, concluded that lung aeration is established more slowly after cesarean than after vaginal delivery; and according to Bonn et al, the relative delay in aeration is greater when delivery is by cesarean section before the onset of labor (elective section) than when it is by section after some hours of labor. Obviously, these differences probably have nothing to do with squeezing the fetal thorax in the birth canal (Chiswick \& Milner, 1976; Milner et al., 1978; Bonn et al., 1981).

These observations may explain the results of several studies that have described an increased risk of respiratory morbidity within each gestational week from 37 to 39 weeks among infants delivered by elective cesarean section. In a retrospective study of 1,284 elective cesarean deliveries, Zanardo et al reported that respiratory distress syndrome was diagnosed at a rate of 25 per 1,000 live births when cesarean delivery occurred between 37 $0 / 7$ weeks and $386 / 7$ weeks of gestation, versus a significantly lower rate of respiratory distress syndrome, 7 per 1,000, with cesarean delivery after $390 / 7$ weeks of gestation. Neonatal respiratory distress syndrome with vaginal deliveries did not vary $(3-4 / 1000)$ across these gestational ages (Zanardo et al., 2004). Hansen et al assessed the association between elective cesarean sections and neonatal respiratory morbidity and the timing of elective cesarean sections. This was a prospective cohort study that included 2687 infants, without malformations, delivered by elective cesarean section in Denmark. Main outcome measures were respiratory morbidity (transitory tachypnoea of the newborn, respiratory distress syndrome, persistent pulmonary hypertension of the newborn) and serious respiratory morbidity (oxygen therapy for more than two days, nasal continuous positive airway pressure, or need for mechanical ventilation). Compared with newborns intended for vaginal delivery, an increased risk of respiratory morbidity within each gestational week from 37 to 39 weeks was found for infants delivered by elective cesarean section. At 37 weeks' gestation the odds ratio was about 4 folds (95\% confidence interval 2.4 to 6.5 ), 3 folds at 38 weeks' gestation (95\% confidence interval 2.1 to 4.3 ), and 1.9 folds at 39 weeks' gestation (95\% confidence interval 1.2 to 3.0 ). The increased risks of serious respiratory morbidity showed the same pattern, with 5 folds increase for infants delivered at 37 weeks' gestation, 4 folds increase for infants delivered at 38 weeks, and more than 2 folds increase for infants delivered at 39 weeks, although the increased risk at 39 weeks was not statistically significant. These results remained essentially unchanged after exclusion of pregnancies complicated by diabetes, pre-eclampsia, and intrauterine growth retardation, or by breech presentation (Hansen et al., 2008).

Tita et al studied a cohort of consecutive women undergoing repeat cesarean sections performed at 19 centers of the Eunice Kennedy Shriver National Institute of Child Health and Human Development Maternal-Fetal Medicine Units Network from 1999 through 2002. Women with viable singleton pregnancies delivered electively were included. The primary outcome was the composite of neonatal death and any of several adverse events, including respiratory complications, treated hypoglycemia, newborn sepsis, and admission to the neonatal intensive care unit. The study included 13,258 cesarean deliveries performed electively. As compared with births at 39 weeks, births at 37 weeks were associated with a 2.1 folds increase in the risk of the primary outcome (95\% confidence interval 1.7 to 2.5 ) and 1.5 folds for births at 38 weeks (95\% confidence interval 1.3 to 1.7). The rates of adverse respiratory outcomes, mechanical ventilation, newborn sepsis, hypoglycemia, admission to 
the neonatal intensive care unit, and hospitalization for 5 days or more were increased by a factor of 1.8 to 4.2 for births at 37 weeks and 1.3 to 2.1 for births at 38 weeks (Tita et al., 2009).

The results of the above studies were confirmed by other studies that demonstrated consistently an increased neonatal respiratory morbidity with elective cesarean delivery performed earlier than 39 weeks.

\subsection{Maternal benefits}

A secondary analysis of the Cesarean Section Registry of the Eunice Kennedy Shriver National Institute of Child Health and Human Development Maternal Fetal-Medicine Units (NICHD MFMU) Network, reported maternal outcomes with regard to gestational age at delivery. The study included women with live singleton pregnancies delivered by prelabor elective repeat cesarean delivery from 1999 through 2002 at 19 U.S. academic centers. Gestational age was examined by completed weeks. Maternal outcomes included a primary composite of death, hysterectomy, uterine rupture or dehiscence, blood transfusion, uterine atony, thromboembolic complications, anesthetic complications, surgical injury or need for arterial ligation, intensive care unit admission, wound complications, or endometritis. The results demonstrated a comparable maternal outcome at 37, 38 and 39 weeks of gestation. In view of that, combined with the fact that neonatal morbidity is higher at births before 39 weeks, the authors recommended scheduling elective cesarean to 39 weeks (Tita et al., 20110). Nonetheless, the results of the above study were soon after challenged, and a letter to the editor was later published (Salim and Shalev, 2011).

\subsection{Fetal and neonatal consequences related to delaying cesarean to 39 weeks}

Women assigned to an elective cesarean delivery may go into labor prior to the scheduled date of surgery. About $10 \%$ to $14 \%$ of women may go into spontaneous labor between 38 and 39 weeks of gestation (Salim \& Shalev, 2010; Thomas \& Paranjothy, 2001). Hansen et al reported that up to $25 \%$ of women may enter labor before 39 weeks (Hansen et al., 2008). Laboring women might present during the early stages of labor, with or without membrane ruptures, or alternatively they may present during advanced stages of labor. Maternal and neonatal outcomes may be adversely affected when cesarean delivery is preceded by labor, even if labor is not advanced.

\subsubsection{Fetal and neonatal morbidity}

The implication of scheduling delivery to 39 weeks is that a proportion of elective cesarean deliveries will convert to non-elective ones, which may increase the risk of traumatic injury to the fetus/newborn (Hankins et al., 2006). The reported incidence of iatrogenic fetal trauma during cesarean delivery is $0.1 \%$ to $1.9 \%$ of births (Aburezq et al., 2005). Several risk factors for fetal injury at the time of the cesarean delivery have been identified through various case reports. These include lack of surgical experience, labor with thinning of the lower uterine segment exposing the fetus to injury with the scalpel, and a lack of amniotic fluid secondary to rupture of the membranes making the underlying fetal parts more accessible (Haas \& Ayres, 2002; Puza et al., 1998). Fetal lacerations, finger injuries and amputations, penetrating brain injuries, skull fractures and long bone fractures have all been 
reported from the use of the scalpel or scissors at the time of cesarean delivery [3]. Although traumatic delivery is still associated with cesarean delivery, it is uncommon with elective, compared to non-elective cesarean delivery of the vertex fetus at term (Hankins et al., 2006).

In the term breech trial, $6 \%$ of women who were assigned to a planned cesarean delivery, delivered vaginally because cesarean delivery was not possible due to imminent vaginal delivery (Hannah et al., 2000). Perinatal mortality and serious neonatal morbidity of the breech presenting fetus are significantly lower in planned cesarean delivery than for vaginal birth according to the term breech trail. Delaying an elective cesarean delivery scheduled for breech presentation may expose some of the fetuses to preventable morbidity and mortality associated with vaginal breech delivery in cases where vaginal delivery is imminent at admission.

Delaying delivery until 39 weeks increases the time that the woman and her fetus is vulnerable to a number of unexpected complications and increases the proportion of women who may present in labor. The incidence of meconium staining of amniotic fluid has been reported to increase with increasing gestational age above 37 weeks of gestation (Saunders \& Paterson, 1991). In addition, it is acknowledged that the process of labor may itself produce an encephalopathic response in infants who were previously injured and who are simply unable to make the usual compensatory responses to the stresses of labor (Hankins et al., 2006). This issue is crucial if women present during the advanced stages of labor before the scheduled cesarean.

\subsubsection{Intrauterine fetal demise}

An accumulative increased risk of intrauterine fetal death has been reported with increasing gestational age. Copper et al reported that the timing of fetal death for stillborn infants born between 23 and 40 weeks is evenly distributed with nearly $5 \%$ of all stillbirths occurring per week of gestation (Copper et al., 1994). This is important when considering all stillborn infants at 38 weeks and beyond, where significant complications of prematurity would be very rare if only these fetuses had simply been delivered earlier. Furthermore, it has been reported that a fairly stable rate of fetal death of 0.6 per 1000 live births occurs from 33 weeks to 39 weeks of gestation. However, at 39 weeks, the rate increases significantly to 1.9 per 1000 live births (Yudkin et al., 1987).

Others reported a fetal death rate per 1000 live births at weekly intervals from 37 to 41 weeks increasing from 1.3 at 37 weeks to 2.0 at 38 weeks, 2.9 at 39 weeks, 3.8 at 40 weeks, and 4.6 at 41 weeks of gestation (Fretts et al., 2004). It is clear that delivery at 38 weeks compared to 39 weeks or more would reduce intrauterine fetal deaths.

Ehrenthal et al evaluated the association of a new institutional policy limiting elective delivery before 39 weeks of gestation with neonatal outcome (Ehrenthal et al., 2011). This was a retrospective cohort study that was conducted to estimate the effect of the policy on neonatal outcome using a before and after design. All term singleton deliveries 2 years before and 2 years after policy enforcement were included. The results confirmed that a policy limiting elective delivery before 39 weeks of gestation was accompanied by a significant increase in the incidence of still birth (RR 3.67, 95\% CI 1.02-13.15, P=.032).

De la Vega and coworkers in a mixed risk population with unrestricted access to testing for fetal wellbeing and sonographic evaluations concluded that, despite intensive surveillance, 
they were still unable to reduce the rate of fetal death. The investigators suggested that this is probably due to occurrence of acute placental and cord accidents that cannot be detected through antenatal fetal surveillance and are simply unavoidable (de la Vega et al,. 2002).

The sudden death of a fetus in utero has medical, social and economic implications. It is particularly tragic when it occurs shortly before the expected date of delivery.

\subsection{Maternal consequences}

As mentioned earlier women assigned to elective cesarean delivery and go into spontaneous labor, may present in early stages of labor with or without ruptured membranes or alternatively they may present at advanced stages of labor. As a result, maternal outcome may be affected due to the advance labor that preceded the scheduled cesarean delivery. In other precise situations, even when early stages of labor with or without ruptured membranes precede the scheduled cesarean delivery, maternal outcome may still be affected.

\subsubsection{Perioperative complications}

The rate of severe maternal morbidity caused by different modes of delivery among all singleton deliveries was studied in Finland in 1997 and 2002. Main outcome measures were deep venous thromboembolism, amniotic fluid embolism, major puerperal infection, severe hemorrhage, uterine rupture or inversion and intestinal obstruction. Severe maternal morbidity was significantly more frequent in non-elective than in elective operations. Moreover, operative interventions after the delivery was significantly more frequent after non-elective cesarean delivery than after elective cesarean delivery. There were more severe complications in the group of women older than 35 years than in the younger women (Pallasmaa et al., 2008). In another retrospective study, the prevalence and risk factors for bladder injury during cesarean delivery were investigated. Operator experience and the emergency nature of the cesarean delivery were both considered risk factors for bladder injury (Rahman et al., 2009).

\subsubsection{Uterine rupture}

The overall risk of uterine rupture for women with a prior cesarean delivery is higher among women undergoing a subsequent trial of labor as compared to elective cesarean delivery. Other than maternal morbidity, a ruptured uterus carries a greater risk for hypoxic-ischemic encephalopathy and perinatal deaths (Landon et al., 2004). The risk of rupture is greater among women after higher order repeated cesarean delivery and it had been reported to occur five times greater among women with 2 prior cesarean scars compared to women with only 1 prior cesarean scar (3.7\% vs $0.8 \%$, respectively) (Caughey et al,. 1999).

The risk of rupture is probably greater among parous women with multiple repeated cesarean deliveries, a situation commonly encountered in some regions. Patients with prior classical hysterotomies have been reported to have an even higher incidence of uterine rupture. Rupture has been reported to occur in many of these women even before the onset of labor (Halperin et al., 1988). Although the incidence of uterine rupture mentioned above has been reported to occur among women after a trial of labor, still, it's not rare to encounter women assigned to elective cesarean delivery, to present in advance stages of labor. 


\subsubsection{Anesthesia related complications}

Failed intubation and pulmonary aspiration are the leading causes of anesthesia-related maternal morbidity and mortality. Fasting for a period of 6 to 8 hours is recommended before elective cesarean delivery (American College of Obstetrics and Gynecology [ACOG], 2002). Women scheduled for an elective cesarean delivery and who go into spontaneous labor may present while not in the fasting state. Performing an immediate cesarean delivery because the woman is in labor increases maternal morbidity and mortality. Alternatively, delaying the procedure 6 to 8 hours may increase the risk of converting early stages of labor to advance stages which may complicate the procedure. Furthermore, women whose indication for cesarean delivery human immunodeficiency virus infection or genital herpes, the risk of neonatal infection may increase if abdominal delivery is delayed.

\subsubsection{Non surgical complications}

Delaying delivery until 39 weeks has other non-surgical consequences. The rates of gestational hypertension, preeclampsia, and eclampsia increase from 37 to 42 weeks when calculated according to ongoing pregnancy (Caughey et al., 2003).

\subsubsection{Urinary incontinence}

Women with severe urinary incontinence have a marked deterioration in their quality of life, most substantially curtail activities, many become homebound, and for some, urinary incontinence is the defining event that prompts nursing home admission. In the United States each year, an estimated 135,000 women undergo surgery for urinary incontinence (Waetjen et al., 2003). An estimate of direct costs for urinary incontinence in the United States has been reported to be $\$ 16$ billion per year (Wilson et al., 2001). Given the substantial public health burden of pelvic floor disorders, much research attention has been focused on identifying risk factors, especially modifiable risk factors, for the development of pelvic floor disorders. Many retrospective and cross-sectional studies implicate childbirth as a major risk factor for urinary incontinence in younger women. Whether, and to what degree, cesarean delivery may protect child-bearing women from developing urinary incontinence is an unresolved issue. Several prospective studies evaluated the risk of postpartum urinary incontinence by delivery type, grouping all cesarean deliveries together and reported inconsistent results.

The best data to investigate in order to evaluate the impact of cesarean delivery is that which separates out cesarean deliveries done before and after the onset of labor. Farrell et al assessed the incidence of urinary incontinence, 6 weeks postpartum according to the mode of delivery. After forceps delivery, the incidence was 35\%, 23\% after spontaneous vaginal delivery, 9\% after cesarean during labor and 4\% after cesarean before labor. By 6 months, these prevalence figures were $33 \%, 22 \%, 12 \%$, and 5\%, respectively (Farrell et al., 2001).

Chin et al assessed the impact of delivery on the pelvic floor and to what degree could cesarean delivery prevent pelvic floor injury. Five hundred thirty nine women were divided into three groups according to the delivery method adopted: elective cesarean delivery, emergent cesarean delivery, and vaginal delivery. Only elective cesarean delivery was protective. They concluded that the key to the best protection against postpartum urinary incontinence seems to lie in the timing of the cesarean delivery; that is, the cesarean delivery 
has to be performed before labor or uterine contractions have commenced. In view of that, not all cesarean deliveries can be considered as a superior alternative for pelvic floor protection that would decrease the likelihood of postpartum urinary incontinence according to the authors (Chin et al., 2006).

\subsubsection{Maternal mortality}

In 1990, the results of a retrospective review of 108 maternal deaths occurring between 1975 and 1986 in Cape Town, South Africa Lilford were published (Lilford et al., 1990). The data suggested an increased risk of maternal mortality with non-elective intrapartum cesarean deliveries as compared with elective procedures. Another publication reporting on deliveries in Israel between 1984 and 1992 compared maternal mortality among vaginal deliveries, emergency cesarean deliveries, and elective cesarean deliveries. Fifty five cases were reported with an overall mortality rate of 6 per 100,000. Rates of maternal mortality were 2.8, 3.6, and 30 per 100,000 deliveries for elective cesarean deliveries, vaginal delivery, and emergency cesarean deliveries, respectively (Yoles \& Maschiach, 1998).

The Report on Confidential Enquiries into Maternal Deaths, 1997 to 1999, reported the estimated maternal mortality rates and relative risk of direct deaths based on method of delivery. A significant higher maternal mortality rate was observed with emergency and urgent cesarean deliveries (Royal College of Obstetricians and Gynaecologists, 2001).

\subsubsection{Special issue - Advance maternal age}

More women are postponing pregnancy into the forth and fifth decades of life for a variety of reasons. In Finland the reported proportion of women giving birth at age 35 years or more was increased from 16.7\% in 1997 to 19.2\% in 2002 (Pallasmaa et al., 2008). Advanced maternal age, traditionally defined as age over 35 years, has been associated with increased obstetric morbidity and interventions. In addition, perinatal complications are reported to be higher in this patient population (Usta \& Nassar, 2008).

Older women are more likely to have cesarean delivery without labor (Ecker et al., 2001). The risk for severe complications during emergency cesarean delivery in the group of women older than 35 years is higher than in the younger ones (Pallasmaa et al., 2008). Furthermore, intrauterine fetal death and perinatal mortality are significantly higher in older women even after excluding deaths due to congenital malformations and adjusting for existing illnesses or pregnancy complications (Jacobsson et al., 2004; Joseph et al., 2005). The highest rate of stillbirth was reported to occur among older women after 38 weeks of gestation (Smith, 2001).

\subsection{Health care provider type and professional resources}

The availability of resources, such as operating rooms and staff, may influence a health care provider's decision regarding when to schedule the date of the elective cesarean delivery. Non-elective cesarean deliveries, which by definition are poorly timed, may result in a patient that presents in the non fasting state, at a time that the hospital is staffed with less experienced surgeons and anesthetists whose skills are further compromised due to demanding working hours. All these factors present additional challenges to the patients' safety. One of the advantages of scheduled operations is the greater ease of balancing 
staffing levels with clinical volume. Inadequate levels of staffing, as well as fatigue among health care providers, may contribute to increased patient morbidity (Minkoff \& Chervenak, 2003; Tucker, 2002).

\section{Conclusion}

Because of increased rates of neonatal respiratory complications, the literature is almost unanimously in favor of delaying elective cesarean delivery until 39 weeks of gestation unless there is evidence of fetal lung maturity. However, multiple chance events may influence outcome. For example, an elective cesarean delivery at 38 weeks may result in the delivery of an iatrogenically premature infant at risk for respiratory morbidity. On the other hand, delaying delivery to 39 weeks may result in an unexplained stillbirth, or spontaneous onset of labor with intrapartum complications that may compromise maternal and neonatal well-being. Decision analysis is a quantitative methodology for evaluating competing strategies under conditions of uncertainty.

About $14 \%$ of all women booked for an elective cesarean delivery at exactly 39 weeks and 0 days, would be expected to go into spontaneous labor between 38 to 39 weeks. For an average hospital with 4500 births a year, and a 10\% elective cesarean delivery rate, scheduling delivery at 38 weeks rather than 39 weeks will result in an additional 10 neonates with respiratory morbidity a year, assuming an additional $2 \%$ neonatal morbidity for those delivered at 38 weeks as compared to 39 weeks (Tita et al., 2009). On the other hand, 63 non-elective cesarean deliveries would be prevented. In fact, since it is not feasible to book all women to exactly 39 weeks and 0 days, particularly in public medical centers, the number of non-elective operations that would be prevented may actually be higher. Other than decreasing the risk of non-elective cesareans, scheduling elective cesarean deliveries to 38 weeks may prevent cases of fetal death especially among older women.

Until prospective randomized trials are conducted, it is not easy to precisely answer all risk:benefit questions as to the best timing of when to schedule elective cesarean delivery; 38 or 39 weeks. Since several studies indicated that neonatal outcomes are improved by delaying cesarean until 39 weeks of gestation, the American College of Obstetricians and Gynecologists as well, recommended delaying cesarean delivery until 39 weeks of gestation in the absence of obstetric or medical indications for early delivery.

However, if dating is confirmed with an ultrasound study prior to 20 weeks of gestation, scheduling cesarean delivery at $380 / 7$ weeks to 38 6/7 weeks may be, in my opinion, another reasonable and alternative option to 39 weeks. This is particularly true among a selected group of women, namely older women and women where a complicated cesarean delivery is anticipated. It is reasonable to inform women of the risks entailed with each of the above options. The clinician's role should be to provide the best evidence-based counseling possible to the woman, and to respect her autonomy and decision-making.

\section{References}

Aburezq, H., Chakrabarty, KH., \& Zuker, RM. (2005). Iatrogenic fetal injury. Obstetrics and Gynecology, Vol.106, No.5 Pt 2, (November 2005), pp. 1720-1174, ISSN 0029-7844. 
American College of Obstetrics and Gynecology. (2002). ACOG practice bulletin. Obstetric analgesia and anesthesia. Number 36, July 2002. American College of Obstetrics and Gynecology. International Journal of Gynecology \& Obstetrics, Vol.78, No.3, (September 2002), pp. 321-335, ISSN 1879-3479.

Ballard, PL. (1986). Hormones and Lung Maturation. Springer-Verlag, Berlin, Heidelberg.

Baines, DL., Folkesson, HG., Norlin, A., Bingle, CD., Yuan, HT., \& Olver, RE. (2000). The influence of mode of delivery, hormonal status and postnatal $\mathrm{O} 2$ environment on epithelial sodium channel $(\mathrm{ENaC})$ expression in perinatal guinea-pig lung. Journal of Physiology, Vol.522, No. Pt1, (January 2000), pp. 147-157, ISSN 1469-7793.

Bassett, JM., \& Thorburn, GD. (1969). Foetal plasma corticosteroids and the initiation of parturition in sheep. Journal of Endocrinology, Vol.44, No.2, (June 1969), pp. 285286, ISSN 1479-6805.

Barker, PM., Walters, DV., Markiewicz, M., \& Strang, LB. (1991). Development of the lung liquid reabsorptive mechanism in fetal sheep: synergism of triiodothyronine and hydrocortisone. Journal of Physiology, Vol.433, (February 1991), pp. 435-449, ISSN 1469-7793.

Berger, PJ., Smolich, JJ., Ramsden, CA., \& Walker, AM. (1996). Effect of lung liquid volume on respiratory performance after Caesarean delivery in the lamb. Journal of Physiology, Vol.492, No.Pt3, (May 1996), pp. 905-912, ISSN 1469-7793.

Berger PJ, Kyriakides MA, Smolich JJ, Ramsden CA, Walker AM. (1998). Massive decline in lung liquid before vaginal delivery at term in the fetal lamb. American Journal of Obstetrics and Gynecology, Vol.178, No.2, (February 1998), pp. 223-227, ISSN 10976868.

Bland, RD., Mcmillan, DD., \& Bressack, MA. (1979). Labor decreases lung water content of newborn rabbits. American Journal of Obstetrics and Gynecology, Vol.134, No.3, (October 1979), pp. 364-367, ISSN 1097-6868.

Bonn, AW., Milner, AD. \& Hopkin, JG. (1981). Lung volumes and lung mechanics in babies born vaginally and by elective and emergency Caesarean section. The Journal of pediatrics, Vol.98, No.5, (May 1978), pp. 812-815, ISSN 1097-6833.

Brice, JEH., \& Wailker, CHM. (1977). Changing pattern of respiratory distress in newborn. Lancet, Vol.2, No.8041, (October 1977), pp. 752-754, ISSN 1476-547X.

Brown, MJ., Olver, RE., Ramsden, CA., Strang, LB., \& Walters, DV. (1983). Effects of adrenaline and of spontaneous labor on the secretion and absorption of lung liquid in the fetal lamb. Journal of Physiology, Vol.344, (November 1983), pp. 137-152, ISSN 1469-7793.

Caughey, AB., Stotland, NE., \& Escobar, GJ. (2003). What is the best measure of maternal complications of term pregnancy: ongoing pregnancies or pregnancies delivered? American Journal of Obstetrics and Gynecology, Vol.189, No.4, (October 2003), pp. 1047-1052, ISSN 1097-6868.

Caughey, AB., Shipp, TD., Repke, JT., Zelop, CM., Cohen, A., \& Lieberman, E. (1999). Rate of uterine rupture during a trial of labor in women with one or two prior cesarean deliveries. American Journal of Obstetrics and Gynecology, Vol.181, No.4, (October 1999), pp. 872-876, ISSN 1097-6868.

Chin, HY., Chen, MC., Liu, YH., \& Wang, KH. (2006). Postpartum urinary incontinence: a comparison of vaginal delivery, elective, and emergent cesarean section. 
International Urogynecology Journal and Pelvic Floor Dysfunction, Vol.17, No.6, (November 2006), pp. 631-635, ISSN 1433-3023.

Chiswick, M., \& Milner, RDG. (1976). Crying vital capacity. Measurement of neonatal lung function. Archives of disease in childhood, Vol.51, No.1, (January 1976), pp. 22-27, ISSN 1468-2044.

Copper, RL., Goldenberg, RL., Dubard, MB., \& Davis, RO. (1994). Risk factors for fetal death in white, black, and Hispanic women. Collaborative Group on Preterm Birth Prevention. Obstetrics and Gynecology, Vol.84, No.4, (October 1994), pp. 490-495, ISSN 0029-7844.

de la Vega, A., \& Verdiales, M. (2002). Failure of intensive fetal monitoring and ultrasound in reducing the stillbirth rate. Puerto Rico health sciences journal, Vol.21, No.2, (June 2002), pp. 123-125, ISSN 0738-0658.

Department of Health, Scottish Executive Health Department, and Department of Health, Social Services and Public Safety, Northern Ireland. Why Mothers Die. Fifth Report on Confidential Enquiries into Maternal Deaths in the United Kingdom, 1997-1999. 2001 London, RCOG Press.

Dickson, KA., Maloney, JE., \& Berger, PJ. (1986). Decline in lung liquid volume before labor in fetal lambs. Journal of Applied Physiology, Vol.61, No.6, (December 1986), pp. 22662272, ISSN 1522-1601.

Ecker, JL., Chen, KT., Cohen, AP., Riley, LE.,\& Lieberman, ES. (2001). Increased risk of cesarean delivery with advancing maternal age: indications and associated factors in nulliparous women. American Journal of Obstetrics and Gynecology, Vol.185, No.4, (October 2003), pp. 883-887, ISSN 1097-6868.

Ehrenthal DB, Hoffman MK, Jiang X, Ostrum G. (2011). Neonatal outcomes after implementation of guidelines limiting elective delivery before 39 weeks of gestation. Obstetrics and Gynecology, Vol.118, No. 5, (November 2011), pp.1047-1055, ISSN 0029-7844.

Farrell, SA., Allen, VM., \& Baskett, TF. (2001). Parturition and urinary incontinence in primiparas. Obstetrics and Gynecology, Vol.97, No.3, (March 2001), pp. 350-356, ISSN 0029-7844.

Fraser, M., \& Liggins, GC. (1988). Thyroid hormone kinetics during late pregnancy in the ovine fetus. Journal of Developmental Physiology, Vol.10, No.5, (October 1969), pp. 461-471, ISSN 0141-9846.

Fretts, RC., Elkin, EB., Myers, ER., \& Heffner, LJ. (2004). Should older women have antepartum testing to prevent unexplained stillbirth? Obstetrics and Gynecology, Vol.104, No.1, (July 2004), pp. 56-64, ISSN 0029-7844.

Gowen CW Jr, Lawson EE, Gingras J, Boucher RC, Gatzy JT, Knowles MR. (1988). Electrical potential difference and ion transport across nasal epithelium of term neonates: correlation with mode of delivery, transient tachypnea of the newborn, and respiratory rate. The Journal of pediatrics, Vol.113, No.1Pt1, (July 1988), pp. 121-127, ISSN 0022-6833.

Haas, DM., \& Ayres, AW. (2002). Laceration injury at cesarean section. Journal of MaternalFetal and Neonatal Medicine, Vol.11, No.3, (March 2002), pp. 196-198, ISSN 1476-4954.

Hales, KA., Morgan, MlA., \& Thurnau, GR. (1993). Influence of labor and route of delivery on the frequency of respiratory morbidity in term neonates. International Journal of Gynecology and Obstetrics, Vol.43, No. 1, (October 1993), pp. 35-40, ISSN 0020-7292. 
Halperin, ME., Moore, DC., \& Hannah, WJ. (1988). Classical versus low-segment transverse incision for preterm cesarean section: maternal complications and outcome of subsequent pregnancies. British Journal of Obstetrics and Gynecology, Vol.95, No.10, (October 1998), pp. 990-996, ISSN 0528-1471.

Hankins, GD., Clark, SM., \& Munn, MB. (2006). Cesarean section on request at 39 weeks: impact on shoulder dystocia, fetal trauma, neonatal encephalopathy, and intrauterine fetal demise. Seminars in Perinatology, Vol.30, No.5, (October 2006), pp. 276-287, ISSN 0146-0005.

Hannah, ME., Hannah, WJ., Hewson, SA., Hodnett, ED., Saigal, S., \& Willan, AR. (2000). Planned caesarean section versus planned vaginal birth for breech presentation at term: a randomised multicentre trial. Term Breech Trial Collaborative Group. Lancet, Vol.356, No.9239, (October 2000), pp. 1375-1383, ISSN 1476-547X.

Hansen, AK., Wisborg, K., Uldbjerg, N., \& Henriksen, TB. (2008). Risk of respiratory morbidity in term infants delivered by elective caesarean section: cohort study. British Medical Journal, Vol.336, No.7635, (January 2008), pp. 85-87, ISSN 0007-1447.

Jacobsson, B., Ladfors, L., Milsom I. (2004). Advanced maternal age and adverse perinatal outcome. Obstet Gynecol 2004;104:727-33. Obstetrics and Gynecology, Vol.104, No.4, (October 2004), pp. 727-733, ISSN 0029-7844.

Joseph, KS., Allen, AC., Dodds, L., Turner, LA., Scott, H., \& Liston, R. (2005). The perinatal effects of delayed childbearing. Obstetrics and Gynecology, Vol.105, No.6, (June 2005), pp. 1410-1418, ISSN 0029-7844.

Kitterman, JA., Ballard, PL., Clements, JA., Mescher, EJ., \& Tooley, WH. (1979). Tracheal fluid in fetal lambs: spontaneous decrease prior to birth. Journal of Applied Physiology, Vol.47, No.5, (November 1979), pp. 985-989, ISSN 1522-1601.

Landon, MB., Hauth, JC., Leveno, KJ., Spong, CY., Leindecker, S., Varner, MW., Moawad, AH., Caritis, SN., Harper, M., Wapner, RJ., Sorokin, Y., Miodovnik, M., Carpenter, M., Peaceman, AM., O'Sullivan, MJ., Sibai, B., Langer, O., Thorp, JM., Ramin, SM., Mercer, BM., \& Gabbe, SG. National Institute of Child Health and Human Development Maternal-Fetal Medicine Units Network. (2004). Maternal and perinatal outcomes associated with a trial of labor after prior cesarean delivery. New England Journal of Medicine, Vol.351, No.25, (December 2004), pp. 2581-2589, ISSN 0028-4793.

Liggins, GC., Schellenberg, JC., Mianzai, M., Kitterman, JA., \& Lee, CCH. (1988). Synergism of cortisol and thyrotropinreleasing hormone in lung maturation in fetal sheep. Journal of Applied Physiology, Vol.65, No.4, (October 1988), pp. 1880-1884, ISSN 15221601.

Lilford, RJ., van Coeverden de Groot, HA., Moore, PJ., \& Bingham, P. (1990). The relative risks of caesarean delivery (intrapartum and elective) and vaginal delivery: a detailed analysis to exclude the effects of medical disorder and other acute preexisting physiological disturbances. British Journal of Obstetrics and Gynecology, Vol.97, No.10, (October 1990), pp. 883-892, ISSN 0528-1471.

Martin, JA., Hamilton, BE., Sutton, PD., Ventura, SJ., Menacker, F., \& Munson, ML. (2005). Births: Final data for 2003. National vital statistics reports; vol.54, No.2, Hyattsville, MD: National Center for Health Statistics. 
Meikle, SF., Steiner, CA., Zhang, J., \& Lawrence, WL. (2005). A national estimate of the elective primary cesarean delivery rate. Obstetrics and Gynecology, Vol.115, No.4, (April 2005), pp. 751-756, ISSN 0029-7844.

Mikner, AD., Saunders, RA. \& Hopkin, IE. (1978). Effects of delivery by caesarean section on lung mechanics and lung volume in the human neonate. Archives of Disease in Childhood, Vol.53, No. 7, (July 1978), pp. 545-548, ISSN 1468-2044.

Milner, AD., Saunders, RA., \& Hopkin, IE. (1978). Effects of delivery by Caesarean section on lung mechanics and lung volume in the human neonate. Archives of disease in childhood, Vol.53, No.7, (July 1978), pp. 545-548, ISSN 1468-2044.

Minkoff, H., \& Chervenak, FA. (2003). Elective primary cesarean delivery. New England Journal of Medicine, Vol.348, No.10, (March 2003), pp. 946-950, ISSN 0028-4793.

Oliver, T K Jr., Demis, JA., \& Bates, GD. (1961). Serial bloodgas tensions and acid-base balance during the first hour of life in hutman infants. Acta Paediatrica, Vol.50, (July 1961), pp. 346-360, ISSN 1651-2227.

Olver, RE., \& Strang, LB. (1974). Ion fluxes across the pulmonary epithelium and the secretion of lung liquid in the foetal lamb. Journal of Physiology, Vol.241, No.2, (September 1974), pp. 327-357, ISSN 1469-7793.

Olver, RE., Ramsden, CA., Strang, LB., \& Walters, DV. (1986). The role of amilorideblockade sodium transport in adrenaline-induced lung liquid reabsorption in the fetal lamb. Journal of Physiology, Vol.376, (July 1986), pp. 321-340, ISSN 1469-7793.

Pallasmaa, N., Ekblad, U., Gissler, M. (2008). Severe maternal morbidity and the mode of delivery. Acta obstetricia et gynecologica Scandinavica, Vol.87, No.6, (June 2008), pp. 662-668, ISSN 1600-0412.

Palme-Kilander, C., Tunell, R., \& Chiwel, Y. (1993). Pulmonary gas exchange immediately after birth in spontaneously breathing infants. Archives of Disease in Childhood, Vol.68, No. 1, (January 1993), pp. 6-10, ISSN 1468-2044.

Pfister, RE., Ramsden, CA., Neil, HL., Kyriakides, MA., \& Berger, PJ. (2001). Volume and secretion rate of lung liquid in the final days of gestation and labor in the fetal sheep. Journal of Physiology, Vol.535, No.Pt3, (September 2001), pp. 889-899, ISSN 1469-7793.

Puza, S., Roth, N., Macones, GA., Mennuti, MT., \& Morgan, MA. (1998). Does cesarean section decrease the incidence of major birth trauma? J Perinatol 1998, 18:9-12. Journal of Perinatology, Vol.18, No.1, (January-February 1998), pp. 9-12, ISSN 14765543.

Rahman, MS., Gasem, T., Al Suleiman, SA., Al Jama, FE., ,Burshaid S., \& Rahman, J. (2009). Bladder injuries during cesarean section in a University Hospital: a 25-year review. Archives of Gynecology and Obstetrics, Vol.279, No.3, (March 2009), pp. 349-352, ISSN 1432-0711.

Salim, R., Zafran, N., \& Shalev, E. (2009) Timing of elective repeat cesarean delivery at term [letter]. New England Journal of Medicine, Vol.360, No.15, (April 2009), pp. 1570, ISSN 0028-4793.

Salim, R., \& Shalev, E. (2010). Health implications resulting from the timing of elective cesarean delivery. Reproductive Biology and Endocrinolgy, Vol.8, (June 2010), pp. 68, ISSN 1477-7827. 
Salim, R., \& Shalev, E. (2011). Timing of Elective Repeat Cesarean Delivery at Term and Maternal Perioperative Outcomes [letter]. Obstetrics and Gynecology, Vol.117, No.6, (June 2011), pp. 1437, ISSN 0029-7844.

Saunders, N., \& Paterson, C. (1991). Effect of gestational age on obstetric performance: when is "term" over? Lancet, Vol.338, No.8776, (November 2000), pp. 1190-1192, ISSN 1476-547X.

Smith, GC. (2001). Life-table analysis of the risk of perinatal death at term and post term in singleton pregnancies. American Journal of Obstetrics and Gynecology, Vol.184, No.3, (February 2001), pp. 489-496, ISSN 1097-6868.

Thomas, J., \& Paranjothy, S. (2001). Royal College of Obstetricians and Gynaecologists Clinical Effectiveness Support Unit. The national sentinel caesarean section audit report. London: RCOG Press; 2001.

Tita, AT., Landon, MB., Spong, CY., Lai, Y., Leveno, KJ., Varner, MW., Moawad, AH., Caritis, SN., Meis, PJ., Wapner, RJ., Sorokin, Y., Miodovnik, M., Carpenter, M., Peaceman, AM., O'Sullivan, MJ., Sibai, BM., Langer, O., Thorp, JM., Ramin, SM., \& Mercer, BM.. Eunice Kennedy Shriver NICHD Maternal-Fetal Medicine Units Network. (2009). Timing of elective repeat cesarean delivery at term and neonatal outcomes. New England Journal of Medicine, Vol.360, No.2, (January 2009), pp. 111120, ISSN 0028-4793.

Tita, AT., Lai, Y., Landon, MB., Spong, CY., Leveno, KJ., Varner, MW., Caritis, SN., Meis, PJ., Wapner, RJ., Sorokin, Y., Peaceman, AM., O'Sullivan, MJ., Sibai, BM., Thorp, JM., Ramin, SM., \& Mercer, BM. Eunice Kennedy Shriver National Institute of Child Health and Human Development (NICHD) Maternal-Fetal Medicine Units Network (MFMU). (2011). Timing of elective repeat cesarean delivery at term and maternal perioperative outcomes. Obstetrics and Gynecology, Vol.117, No.2 Pt 1, (February 2011), pp. 280-286, ISSN 0029-7844.

Tucker, J. (2002). UK Neonatal Staffing Study Group: Patient volume, staffing, and workload in relation to risk-adjusted outcomes in a random stratified sample of UK neonatal intensive care units: a prospective evaluation. Lancet, Vol.359, No.9301, (January 2002), pp. 99-107, ISSN 1476-547X.

Usta, IM., \& Nassar, AH. (2008). Advanced maternal age. Part I: obstetric complications. American Journal of Perinatology, Vol.25, No.8, (September 2008), pp. 521-534, ISSN 0735-1631.

Waetjen, LE., Subak, LL., Shenm H., Lin, F., Wang, TH., Vittinghoff, E., \& Brown, JS. (2003). Stress urinary incontinence surgery in the United States. Obstetrics and Gynecology, Vol.101, No.4, (April 2003), pp. 671-676, ISSN 0029-7844.

Wallace, MJ., Hooper, SB., \& Harding, R. (1996). Role of the adrenal glands in the maturation of lung liquid secretory mechanisms in fetal sheep. American Journal of Physiology, Vol.270, No.1Pt2, (January 1996), pp. R33-R40, ISSN 1522-1539.

Wilson L, Brown JS, Shin GP, Luc K, Subak LL. (2001). Annual direct cost of urinary incontinence. Obstetrics and Gynecology, Vol.98, No.3, (September 2001), pp. 398-406, ISSN 0029-7844.

Wood, SL., Chen, S., Ross, S., \& Sauve, R. (2008). The risk of unexplained antepartum stillbirth in second pregnancies following caesarean section in the first pregnancy. British Journal of Obstetrics and Gynecology, Vol.115, No.6, (May 2008), pp. 726-731, ISSN 0528-1471. 
Yoles, I., \& Maschiach, S. (1998). Increased maternal mortality in cesarean delivery as compared to vaginal delivery? American Journal of Obstetrics and Gynecology, Vol.178, (1998), pp. S78, ISSN 1097-6868.

Yudkin, PL., Wood, L., \& Redman, CWG. (1987). Risk of unexplained stillbirth at different gestational ages. Lancet, Vol.1, No.8543, (May 1987), pp. 1192-1194, ISSN 1476-547X.

Zanardo, V., Simbi, AK., Franzoi, M., Solda, G., Salvadori, A., \& Trevisanuto, D. (2004). Neonatal respiratory morbidity risk and mode of delivery at term: influence of timing of elective caesarean delivery. Acta Paediatrica, Vol.93, No.5, (May 2004), pp. 643-647, ISSN 1651-2227. 


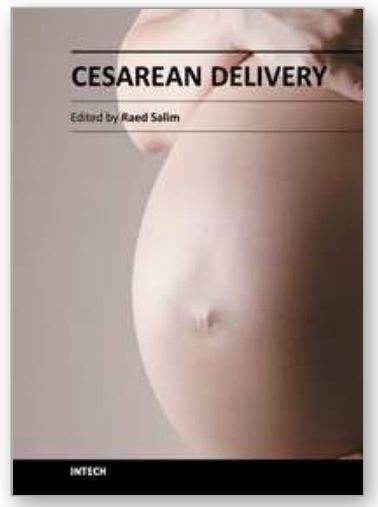

\author{
Cesarean Delivery \\ Edited by Dr. Raed Salim
}

ISBN 978-953-51-0638-8

Hard cover, 200 pages

Publisher InTech

Published online 23, May, 2012

Published in print edition May, 2012

This book provides broad, science-based information regarding the most common major surgical procedure performed, i.e. Cesarean Delivery. The book provides relevant scientific literature regarding epidemiology and rates of cesarean delivery in low and high income countries and the impact of the disparities in the rate of cesarean delivery between countries. In addition, the book systematically reviews the relevant scientific literature regarding all perioperative considerations with a broad cover of anesthetic techniques, drugs and difficulties that anesthesiologists may encounter during cesarean delivery. Care of the neonate after cesarean and crucial guidelines for obese women undergoing cesarean are also provided. The book was written by distinguished experts from different disciplines to ensure complete and accurate coverage of the recent scientific and clinical advances and to bring care providers and purchasers up to date including essential information to help improve health care quality.

\title{
How to reference
}

In order to correctly reference this scholarly work, feel free to copy and paste the following:

Raed Salim (2012). Timing of Elective Cesarean Delivery at Term, Cesarean Delivery, Dr. Raed Salim (Ed.), ISBN: 978-953-51-0638-8, InTech, Available from: http://www.intechopen.com/books/cesarean-delivery/timingof-elective-cesarean-delivery-at-term

\section{INTECH}

open science | open minds

\author{
InTech Europe \\ University Campus STeP Ri \\ Slavka Krautzeka 83/A \\ 51000 Rijeka, Croatia \\ Phone: +385 (51) 770447 \\ Fax: +385 (51) 686166 \\ www.intechopen.com
}

\author{
InTech China \\ Unit 405, Office Block, Hotel Equatorial Shanghai \\ No.65, Yan An Road (West), Shanghai, 200040, China \\ 中国上海市延安西路65号上海国际贵都大饭店办公楼 405 单元 \\ Phone: +86-21-62489820 \\ Fax: +86-21-62489821
}


(C) 2012 The Author(s). Licensee IntechOpen. This is an open access article distributed under the terms of the Creative Commons Attribution 3.0 License, which permits unrestricted use, distribution, and reproduction in any medium, provided the original work is properly cited. 